\title{
RESISTIVITY IMAGING IN EASTERN NEVADA USING THE AUDIOMAGNETOTELLURIC METHOD FOR HYDROGEOLOGIC FRAMEWORK STUDIES
}

\author{
Darcy K. McPhee, U.S. Geological Survey, Menlo Park, CA \\ Louise Pellerin, Green Engineering, Inc., Anchorage, AK \\ Bruce A. Chuchel,U.S. Geological Survey, Menlo Park, CA \\ Janet E. Tilden, U.S. Geological Survey, Menlo Park, CA \\ Gary L. Dixon, Southwest Geology, Inc., Blackfoot, ID
}

\begin{abstract}
Inversion of audiomagnetotelluric (AMT) sounding data collected in eastern Nevada shows significant structure within the upper kilometer of the subsurface that defines the geologic framework from which hydrologic models will be developed. We collected AMT data along two profiles in Spring and Cave valleys in 2004-2005, using the Geometrics StrataGem EH4 system, a four-channel, natural and controlled-source tensor system recording in the range of 10-92,000 Hz. Profiles were 12 and $3 \mathrm{~km}$ in length with station spacing of 200-400 m. Two-dimensional inverse models show detailed structure within the alluvial basin including clear transitions between unsaturated and saturated alluvium/volcanic rocks, highly-resistive (>1000 ohm-m) carbonate rocks, and the locations of range-front and intra-basin faults. In addition, our results define the shape of and the depth to the basement surface, which correlates well with depth to basement estimates derived from the inversion of gravity data.
\end{abstract}

\section{Introduction}

The Basin and Range province is an arid, mountainous, sparsely populated region of the western United States. Here, ground water is organized into extensive regional systems (Harrill and Prudic, 1998) where it can flow between adjacent topographic ranges and basins. Primary aquifer units include Paleozoic carbonate rocks and Tertiary volcanics that occur regionally, in addition to Cenozoic basin-fill units (Plume and Carlton, 1988; Dettinger and others, 1995; Harrill and Prudic, 1998).

Because much of the structure that controls the hydrogeology of the valleys in eastern Nevada is obscured by sediments, geophysical investigations are underway to characterize the subsurface structures and framework influencing ground-water resources. In particular, gravity methods have been used to estimate the structure and depth of the basins in eastern Nevada (Scheirer, 2005). Densities of silicic ash-flow tuff units in the area, however, may be comparable to the average density of basin sediment-fill, causing difficulty in resolving the subsurface geometry between the basin-fill and volcanic rocks using the gravity method alone.

In this study, the AMT method was tested in Spring and Cave valleys (Figure 1) to see if it is a feasible approach to map the structure and significantly contribute to the regional hydrological model in a typical Basin and Range setting. In particular, faults and stratigraphy within the valleys, as well as estimates of depth to basement are valuable targets. The AMT method is used to detect variations in the subsurface electrical resistivity, which are largely dependent on the fluid content, porosity, fracturing, and conductive mineral content of the subsurface geology (Vozoff, 1991; Zonge and Hughes, 1991), and hence may serve as a useful tool for mapping subsurface faults, structures, and lithology. Faults, in particular, may have an electrical signature due to the juxtaposition of different resistivity units, the 
existence of offset conductors, or, in the case of major faults, a fault zone conductor. Tables of electrical resistivity for a variety of rocks and minerals can be found in Palacky (1988).

\section{Data Collection}

In 2004-2005, we collected AMT data along two profile lines in Spring and Cave valleys (Figure 1) using the Geometrics StrataGem EH4 system $($, a four-channel, natural and controlled-source tensor system recording in the range of 10 to $92,000 \mathrm{~Hz}$ (Geometrics, 2000). To augment the low signal in the natural field, an unpolarized transmitter comprised of two horizontal-magnetic dipoles was used from 1,000 to $70,000 \mathrm{~Hz}$.

Profile A was located in southern Spring Valley (Figure 1). It extends from the Fortification Range on the west across the valley to the Limestone Hills in the east along a $12.6 \mathrm{~km}$ line with soundings recorded every $200 \mathrm{~m}$, and is approximately perpendicular to the NS geologic strike in Spring Valley. The second line, profile E, is located in southern Cave Valley and extends $3 \mathrm{~km}$ to the west from Sidehill Pass into the valley. Soundings along Profile E were recorded every 200-400 m.

Data were recorded with the electrical (E) field parallel to and perpendicular to the regional geological strike direction. The electric dipole array was in an ' $\mathrm{X}$ ' configuration with the total dipole length of $40 \mathrm{~m}$. Through experimentation we found that the optimal transmitter distance, at which the measurement site is located in the transmitter's far-field and yet receives adequate signal power, was 200 to $300 \mathrm{~m}$ from the receiver array, and we were able to acquire two stations for each transmitter location.

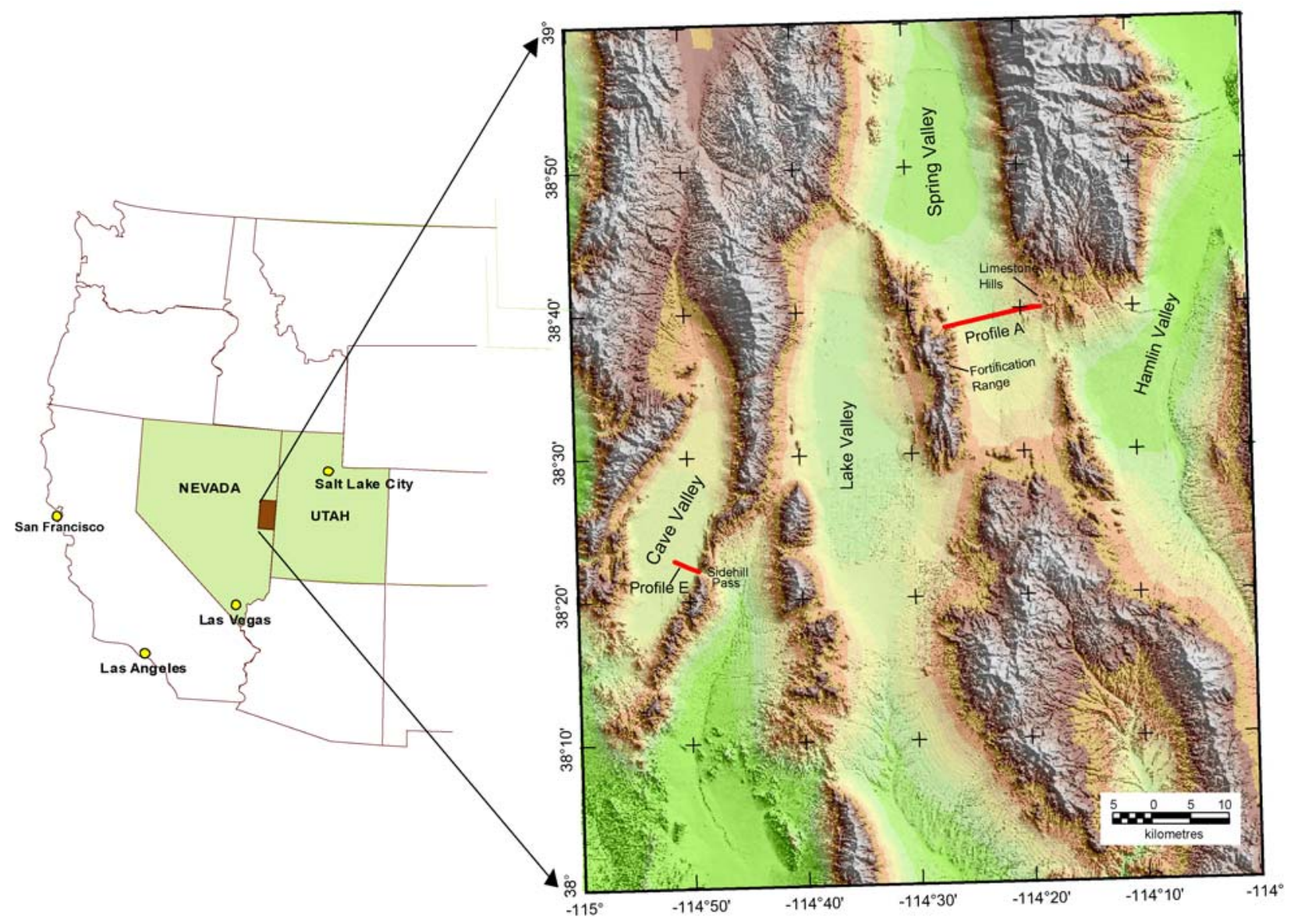

Figure 1: Topographic map of the study area showing locations of AMT profiles in red. 


\section{Results}

We computed two-dimensional (2D), inverse models from the E-perpendicular mode data using the conjugate gradient, finite-difference method of Rodi and Mackie (2001) and a 100 ohm-m half-space starting model with topography. Inverse models were also computed using both the E-parallel and Eperpendicular modes and similar models resulted, with a slightly higher RMS fit supporting the twodimensionality of the structure.

Various starting models were used to test the sensitivity of the model. A half-space starting model of $10 \mathrm{ohm}-\mathrm{m}$ did not produce a model with a resistive basement as would be expected from the Precambrian crystalline basement in this area. Starting half-space models of 100 and 1000 ohm-m produced models that were consistent with a resistive basement as well as with the depth to basement estimates from gravity data (Figures 2 and 4).

The model along Profile A (Figure 2) shows detailed structure revealed by the inverse model within the alluvial basin. The high-quality observed apparent resistivity and phase data show a good fit to the calculated model response as shown in pseudo-section format (Figure 3). In addition, the RMS value was 2.98 for the 64 stations along the $12.6 \mathrm{~km}$ transect. A clear transition between unsaturated (200-500 ohm-m) and saturated alluvium/volcanic rocks (20-50 ohm-m) is present at roughly $100 \mathrm{~m}$ depth. Highly-resistive (>1000 ohm-m) carbonate rocks are well defined at the east end of Profile A under the Limestone Hills, and the locations and dips of several range-front and intra-basin faults, which lack surface expression, can be inferred throughout the upper $1 \mathrm{~km}$ of section.

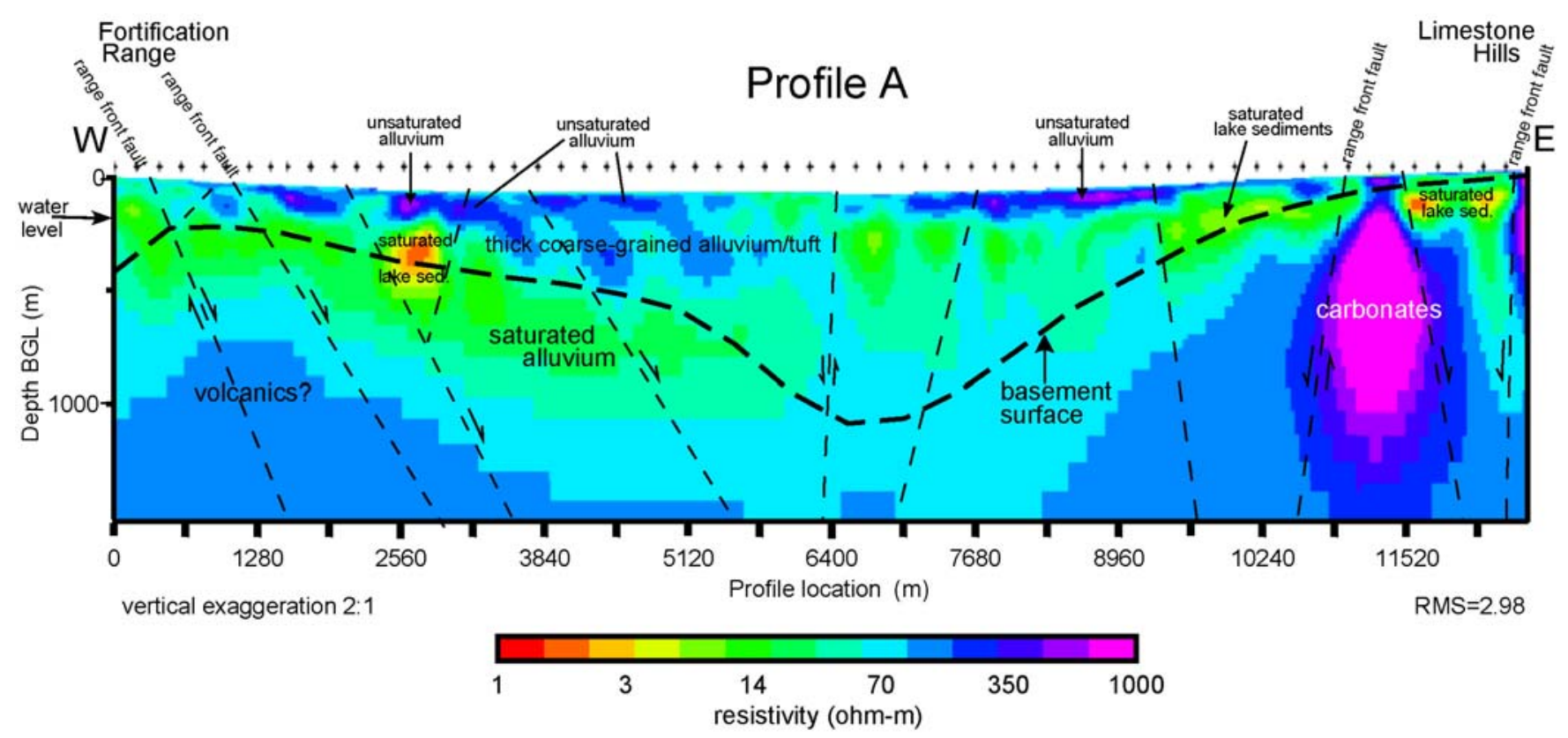

Figure 2: The 2D AMT inverse model and interpretation along Profile A across Spring Valley. Depth to basement estimate derived from gravity data (courtesy of Ed Mankinen, USGS) shown by thick dashed line.

In addition to AMT data, gravity data collected at roughly one-mile spacing throughout Spring Valley and at $200 \mathrm{~m}$ spacing along Profile A were inverted to produce depth to basement estimates using the three-dimensional inverse algorithm of Jachens and Moring (1990). This method assumes density values for the geologic materials present and inverts only on the depth to the basement based on the density contrast between the basement and basin fill. For the frequencies employed and the resistivity of 
the subsurface, the depth to bedrock along Profile A was near the limit of the depth of investigation of the AMT system $(\sim 1 \mathrm{~km})$. The eastern half of the model along Profile A correlates well with depth to basement estimates derived from the inversion of gravity data (Figure 2). Although the depth to basement estimate coincides with a resistivity zone of approximately $20 \mathrm{ohm}-\mathrm{m}$ along the western half of the model, there is no clear resistivity contrast demarcating this surface. The presence of dense volcanics in the western half of the valley may explain the discrepancy between the gravity derived basement depth and the depth of the valley interpreted from the resistivity model.
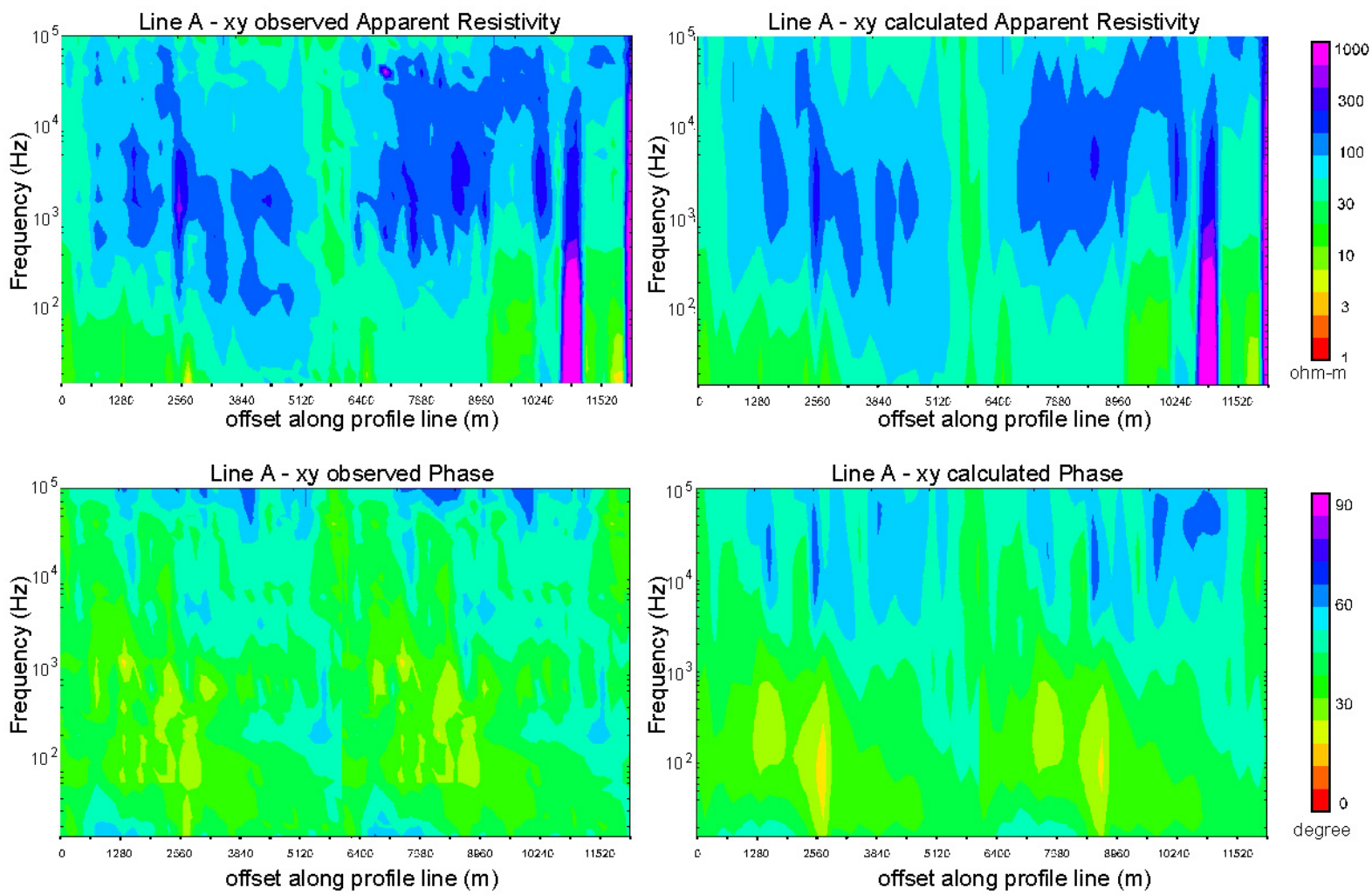

Figure 3: Observed and calculated apparent resistivity and phase data for the 2D model (Figure 2) along Profile A.

The model along Profile E (Figure 4) shows detailed structure on the eastern margin of southern Cave Valley. These data were noisier than those collected along Profile A, especially in the mid band phase (Figure 5), but a reasonable model was obtained with an RMS of 2.93. The upper several hundred meters of the valley shows more conductive alluvial fill (3-20 ohm-m) than was observed in Spring Valley, perhaps due to the additional presence of clays in the valley. As with Profile A, delineated structure within the basin may also indicate the locations of intra-basin faults and the range-front fault to the east defining an uplift of the carbonates.

The abrupt contrast between the resistive limestones on the east side of Cave Valley in the Sidehill Pass area and the more conductive valley fill agrees with the sharp gravity gradient observed by Sheirer (2005), who calculates a steep eastern basin margin that is likely bounded by a range front fault (Figure 4). The depth to basement beyond the eastern margin of Profile E extends deeper than the resolution of our AMT model (Sheirer, 2005). 


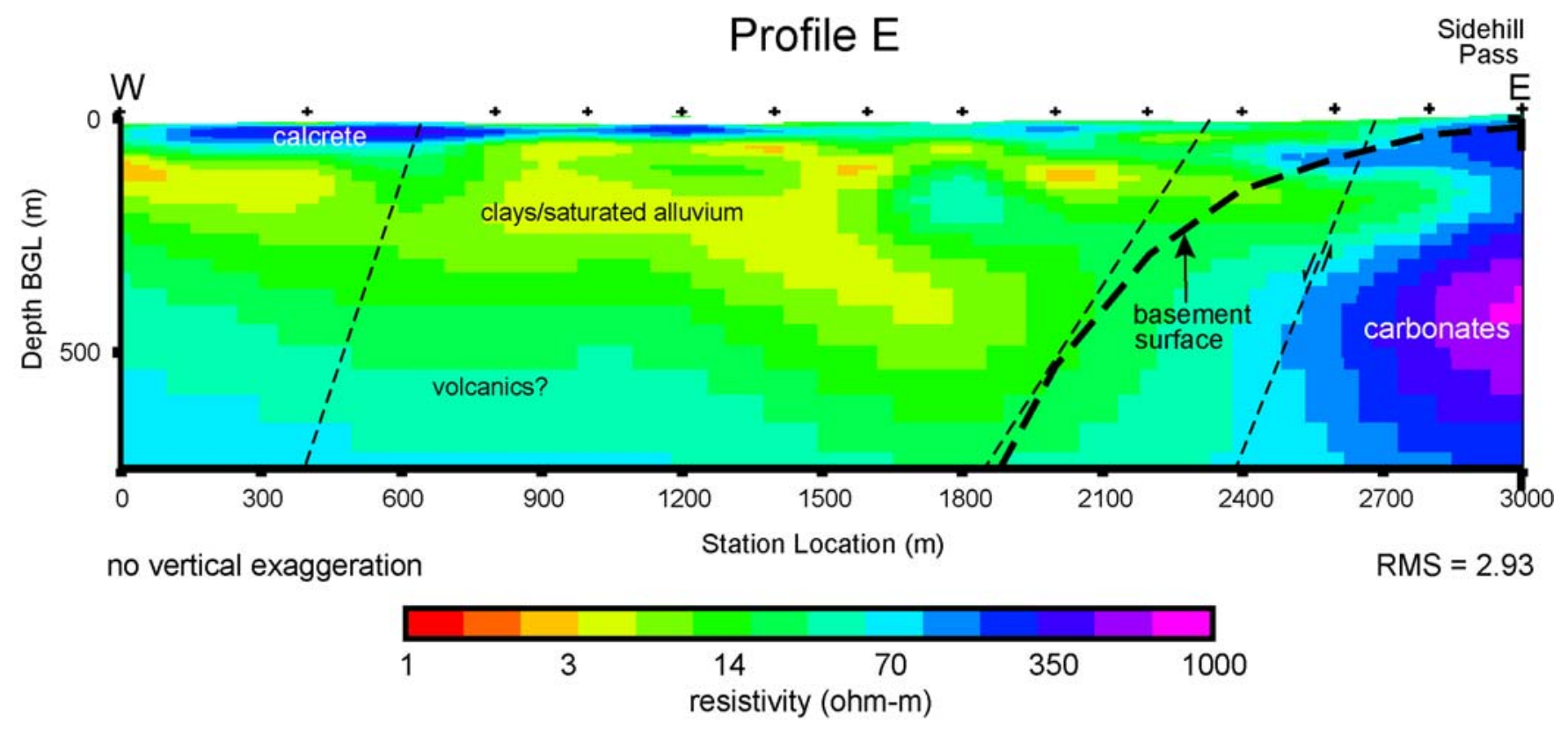

Figure 4: The 2D AMT inverse model and interpretation along Profile E across Cave Valley. Depth to basement estimate derived from gravity data (courtesy of Dan Scheirer, USGS) shown by thick dashed line.

\section{Conclusions}

The AMT method is a valuable tool for revealing subsurface structure and stratigraphy within the Basin and Range of eastern Nevada to depths of approximately $1 \mathrm{~km}$, and therefore helps define the geohydrologic framework in this region. When compared to the basement-surface estimates from the inversion of gravity data in Spring and Cave valleys, the AMT method was successful at estimating the approximate depth to crystalline basement, and the combination of AMT and gravity enhances confidence in these estimates. These basin depths help estimate aquifer locations and volumes as well as the inter-connectedness between neighboring basins. In addition, discrepancies between the gravity derived basement surface estimates and the resistiviy model may help identify potential aquifers, such as volcanics, within the valley.

AMT also shows intra-basin and range-front faults and structures within the valleys. The identification of intra-basin structure will aid in the identification of potential aquifer units, and faults may control groundwater connections in the aquifer system. More AMT data are being acquired in several basins in eastern Nevada, and future research will explore the stratigraphy of the intra-basin structure and its significance to the overall hydrologic framework. 

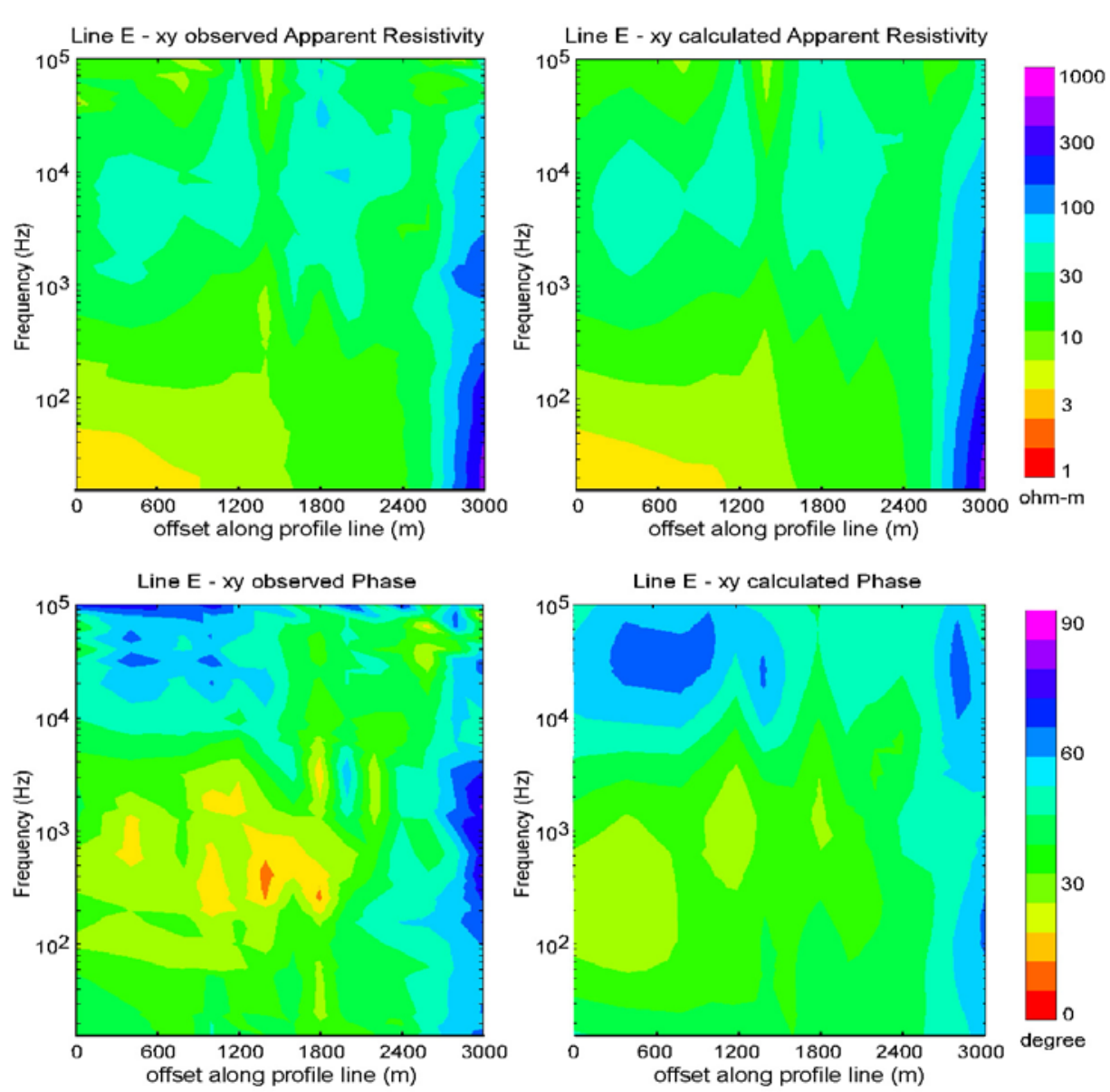

Figure 5: Observed and calculated apparent resistivity and phase data for the 2D model (Figure 4) along Profile E.

\section{References}

Dettinger, M.D., Harrill, J.R., Schmidt, D.L., and Hess, J.W., 1995, Distribution of carbonate-rock aquifers and the potential for their development, southern Nevada and adjacent parts of California, Arizona, and Utah, U.S. Geological Survey Water Resources Investigations Report, 91-4146, 100p.

Geometrics, 2000, Operation manual for Stratagem systems running IMAGEM Ver. 2.16, www.geometrics.com/Stratagem/stratagem.html.

Harrill, J.R., and Pruric, D.E., 1998, Aquifer systems in the Great Basin region of Nevada, Utah and adjacent states - summary report, U.S. Geological Professional Paper, 1409A, 61p.

Jachens, R.C., and Moring, B., 1990, Maps of the thickness of Cenozoic deposits and the isostatic residual gravity over basement for Nevada, U.S. Geological Survey Open File Report, 90-404, 15 p.

Palacky, G.J., 1988, Resistivity characteristics of geologic targets: in Nabighian, M.N., Ed., Electromagnetic methods in applied geophysics, 01: Soc. of Expl. Geophys., 53-130.

Plume, R.W., and Carlton, S.M., 1988, Hydrogeology of the Great Basin region of Nevada, Utah, and adjacent states, U.S. Geological Survey Hydrological Investigations Atlas, HA-694-A, scale $1: 1,000,000$. 
Rodi, W., and Mackie, R. L., 2001, Nonlinear conjugate gradients algorithm for 2D magnetotelluric inversion, Geophysics, 66, 174-187.

Scheirer, D.S., 2005, Gravity studies of Cave, Dry Lake, and Delamar valleys, east-central Nevada, U.S. Geological Survey Open File Report, 2005-1339, 36p.

Vozoff, K., 1991, The magnetotelluric method, in Electromagnetic Methods in Applied Geophysics, Volume 2, Application, Part B, Ed. Nabighian, M.N.: Society of Exploration Geophysicists, Investigation in Geophysics 03, 641-712.

Zonge, K. L. and Hughes, L. J., 1991, Controlled source audio-frequency magnetotellurics, in Nabighian, M. N., Ed., Electromagnetic Methods in Applied Geophysics, 02: Soc. of Expl. Geophys., 713-809.

\section{www.alphageofisica.com.br}

